\title{
Muscles of facial expression in the chimpanzee (Pan troglodytes): descriptive, comparative and phylogenetic contexts
}

\author{
Anne M. Burrows, ${ }^{1,2}$ Bridget M. Waller, ${ }^{3}$ Lisa A. Parr ${ }^{4,5}$ and Christopher J. Bonar ${ }^{6}$ \\ ${ }^{1}$ Department of Physical Therapy, Duquesne University, Pittsburgh, USA \\ ${ }^{2}$ Department of Anthropology, University of Pittsburgh, Pittsburgh, USA \\ ${ }^{3}$ Department of Psychology, University of Portsmouth, UK \\ ${ }^{4}$ Yerkes National Primate Research Center, Atlanta, USA \\ ${ }^{5}$ Department of Psychiatry and Behavioral Sciences, Emory University, Atlanta, USA \\ ${ }^{6}$ Cleveland Metroparks Zoo, USA
}

\begin{abstract}
Facial expressions are a critical mode of non-vocal communication for many mammals, particularly non-human primates. Although chimpanzees (Pan troglodytes) have an elaborate repertoire of facial signals, little is known about the facial expression (i.e. mimetic) musculature underlying these movements, especially when compared with some other catarrhines. Here we present a detailed description of the facial muscles of the chimpanzee, framed in comparative and phylogenetic contexts, through the dissection of preserved faces using a novel approach. The arrangement and appearance of muscles were noted and compared with previous studies of chimpanzees and with prosimians, cercopithecoids and humans. The results showed 23 mimetic muscles in $P$. troglodytes, including a thin sphincter colli muscle, reported previously only in adult prosimians, a bi-layered zygomaticus major muscle and a distinct risorius muscle. The presence of these muscles in such definition supports previous studies that describe an elaborate and highly graded facial communication system in this species that remains qualitatively different from that reported for other non-human primate species. In addition, there are minimal anatomical differences between chimpanzees and humans, contrary to conclusions from previous studies. These results amplify the importance of understanding facial musculature in primate taxa, which may hold great taxonomic value.
\end{abstract}

Key words chimpanzee; hominines; mimetic, phylogeny.

\section{Introduction}

The study of facial expressions and communication has a rich history from Duchenne (1862) to Darwin (1872) and through to the present (e.g. Ekman, 1973; Ekman \& Oster, 1979; Kaiser, 2002). Darwin (1872), in particular, stressed the importance of comparing facial expressions among humans and other mammals in order to understand the evolution of non-vocal communication systems. Additionally, he posited that the means for

Correspondence

Dr Anne M. Burrows, Department of Physical Therapy, Duquesne University, 600 Forbes Ave., Pittsburgh, PA 15282, USA. T: +1 412396

5543; E: burrows@duq.edu

Accepted for publication 26 September 2005 expressing emotion through movements of the face may be similar among humans and other mammals, particularly among the primates. However, there is very little research that has actually attempted to compare the facial expression musculature (mimetic musculature) among primates. This is a particularly important endeavour, as the majority of the literature, although old, adopts a hierarchical ascending phylogenetic model that proposes that as species get more closely related to humans, their communicative facial repertoire and underlying facial musculature become more elaborate (Gregory, 1929; Huber, 1931).

The muscles of facial expression are branchiomeric in origin and are innervated by the seventh cranial nerve (Young, 1957, 1962; Walker \& Liem, 1994). These muscles generally serve to move the vibrissae, change the sizes of the oral, orbital and nasal openings, aid in 
nutrient intake, and function in chemoception, olfaction and audition, and, in non-mammalian orders (excluding Aves), change the size of the gill openings and aid in opening the mouth (Huber, 1930a,b; Young, 1962). In Osteichthyes and Chondrichthyes, these muscles are primarily organized as sphincters to aid in elevation of the mandible and in constriction of the pharynx and gills (Gregory, 1929; Walker \& Liem, 1994). In lower eutherian mammals, such as the Perissodactyla and Artiodactyla, the facial expression musculature is relatively simple in its attachments into the dermis and pinna, is relatively flat and undifferentiated, and is few in number (Sisson, 1921). However, in higher eutherian mammals, especially primates, this musculature is additionally used in transmitting close-proximity social information such as emotional states, territorial intentions, and mate and individual recognition, and is used in a variety of agonistic and conciliatory displays (Darwin, 1872; Huber, 1930a,b, 1931; van Hooff, 1962; Andrew, 1963; Bearder et al. 1995; Preuschoft \& van Hooff, 1995; Schmidt \& Cohn, 2001; Parr et al. 2002, 2005). Indeed, it has been argued that primate facial musculature has been shaped by natural selection specifically to aid communication among individuals (Huber, 1931). However, in contrast to the literature describing facial displays in primate species, the literature describing and comparing the anatomy of the facial muscles is surprisingly sparse. For example, the facial expressions of the chimpanzee (Pan troglodytes), in particular, have received much attention from behavioural scientists (e.g. Marler, 1965, 1976; van Hooff, 1972, 1973; Goodall, 1986; Parr, 2003; Parr et al. 2005), and yet detailed facial dissections are lacking in the literature.

Our understanding of primate mimetic musculature has traditionally been rooted in a phylogenetic context. For example, it is traditionally held that the most primitive primates, the prosimians, have the least complex arrangement of facial expression musculature, consisting of large, relatively undifferentiated sheets of muscle that perform relatively gross, non-specific functions (Huber, 1931; Schultz, 1969). As one moves up the phylogenetic hierarchy toward Homo sapiens, it is held that the number of muscles increases at the level of each taxon and that their function in moving specific facial regions increases as social networks become more intricate (Huber, 1930a,b, 1931; van Hooff, 1962; Schultz, 1969; Preuschoft, 2000). The primate taxa traditionally held to have the least complex (structurally and functionally) facial expression musculature are nocturnal - the lemurs (except for the diurnal Lemur, Varecia, and the indriids and the cathemeral Eulemur and Hapalemur) and lorises (Murie \& Mivart, 1872; Ruge, 1885; Gregory, 1929; Huber, 1931; Lightoller, 1934; Seiler, 1975), while the almost entirely diurnal Anthropoidea are held to have the most complex facial expression musculature and social systems, with Homo sapiens at the apex (e.g. Lightoller, 1928; Gregory, 1929; Huber, 1931, 1933; Schultz, 1969; Pellatt, 1979a,b; Preuschoft, 2000; Stranding, 2004).

Our best understanding of primate facial expression musculature comes from the hominines (the African apes), especially from Homo. Gorilla musculature has been described, but only superficially, by Huber (1931) and Raven (1950). The muscles presented in these accounts are either partially unlabelled and/or not described in the text. Indeed, Huber (1931) used only juveniles in his description. A similar situation exists in Pan troglodytes (Sonntag, 1923; Huber, 1931; Pellatt, 1979b). Overall, the accounts of $P$. troglodytes are problematic in part due to differences in the musculature reported. For example, Sonntag (1923) reports a distinct risorius muscle in $P$. troglodytes while Pellatt (1979b) does not report one. Whether this is due to a genuine difference among the specimens examined or merely represents a different focus between the two studies is unknown. In a recent work, Gibbs et al. (2002) reviewed the existing literature on hominoid softtissue anatomy. The section dealing with the muscles of facial expression was scanty but represented the published accounts to date on all hominoids.

Recent studies have questioned the validity of the traditional 'phylogenetic model' of the complexity of primate facial expression musculature and primate facial displays. For example, Burrows \& Smith (2003) found greater complexity in the facial muscles of Otolemur (the greater bushbaby) than phylogenetic models would predict (see also Murie \& Mivart, 1872). Sherwood et al. $(2003,2005)$ examined the facial nucleus of the brainstem in a variety of primate taxa and found a number of specializations at each taxonomic level, revealing that there is no simple increase in complexity as the phylogenetic scale is ascended towards Homo.

Although conceptualizing primate facial musculature complexity among taxa using the traditional 'phylogenetic model' (Gregory, 1929; Huber, 1931) may not be a completely useful tool, an accurate rendering of 
facial musculature among primate taxa could be a crucial piece of evidence in considering primate evolution (sensu Gibbs et al. 2002). As the chimpanzee is held by many to be the most closely related extant primate to humans (e.g. Groves, 2001; McBrearty \& Jablonski, 2005; The Chimpanzee Sequencing \& Analysis Consortium, 2005), their anatomy and behaviour are often a focus in efforts to comprehend the processes and mechanisms involved in evolution of contemporary Homo (e.g. Hopkins et al. 1993; Fagot \& Bard, 1995; Gibbs et al. 2002; Bard, 2003; Boesch, 2003; Hicks et al. 2005; Pika et al. 2005). The communicative repertoire of the chimpanzee is among the most fully developed of any non-human primate (Goodall, 1986; Parr \& de Waal, 1999; de Waal, 2000). However, there are virtually no studies that fully describe the facial musculature in detail. An understanding of the facial musculature of P. troglodytes may help not only to further our understanding of chimpanzee social behaviour but also to further our understanding of the relationship between Pan and Homo, the significance of facial expression in their respective social systems, and the evolution of facial expression as a means of communication among primates in general.

\section{Materials and methods}

The preserved faces from two adult male Pan troglodytes were used in the present study. One specimen was obtained from the Cleveland Metroparks Zoo (CMZ); the other was obtained from the Yerkes National Primate Research Center (YPRC), Atlanta, GA, USA. Both individuals were adult males and died from natural causes. The face from the $C M Z$ specimen was removed in numerous sections (an ear/scalp section, an orbital/midface section and an oral/lower face section) and immediately preserved in $10 \%$ buffered formalin. The YPRC specimen tissue was removed as one complete mask directly from the head in one large section but only the right side of the face was collected for this study. The head from the YPRC specimen was preserved in $10 \%$ buffered formalin and the face that was removed from this specimen was preserved in the same manner after it was removed.

In the YPRC sample, a midline incision was made over the frontal, nasal and oral regions. Because the brain and most of the calvaria had been previously removed, a midline incision over the scalp and down toward the dorsal cervical region had already been made. From this point, the right side of the face was separated from the left side. All skin, superficial fasciae and superficially located facial expression musculature were dissected away from the more deeply situated facial expression musculature, the buccinator muscle, the masticatory musculature and the bone using no. 11, 12 and 21 scalpel blades and a variety of dissection tools. Care was taken to remove as much superficial facial musculature as possible with the skin and fascia, leaving behind on the skull only those portions of the muscles that had firm bony attachments, such as the origin of the orbicularis oris muscle and the origin of the deep head of the zygomaticus major muscle. Thus, a 'face mask' was created that was separate from the skull. Using this novel approach is more conservative than attempting to filet the skin away from the facial musculature and preserves more superficially located muscles that might be lost in removing the skin from the musculature. In addition, it provides the most complete possible picture of muscle attachments by keeping superficial portions attached to the skin and deeper portions attached to the skull (see Burrows \& Smith, 2003). Thus, the $C M Z$ specimen was only available as a facial mask while the YPRC specimen was available as both the mask plus the deeper portions that were still attached to the skull. However, many superficially located muscle attachments, such as the zygomaticus major muscle attachment into the orbicularis oris muscle, were preserved in the $\mathrm{CMZ}$ specimen.

The face masks were allowed to dry for 15-30 min in order to have the best possible differentiation among muscle, fasciae and other connective tissue. All fasciae and other connective tissue were removed with a variety of dissection tools so that each muscle was identifiable from surrounding muscles and fasciae, and such that its attachments could be clearly seen (see Fig. 2 , for example).

The face masks were examined for the presence of muscles and their attachments as well as any differences between the two specimens. Text and diagrams from a variety of sources were used in order to identify the muscles, including Sonntag (1923), Huber (1931), Pellatt (1979b), Swindler \& Wood (1982), and, for comparative purposes, Raven (1950 - Gorilla), Huber (1933 - Macaca), Swindler \& Wood (1982 - Papio) and Stranding (2004-Homo). All soft-tissue attachments for each muscle into the dermis and into other musculature and bones of the skull were noted and recorded, as was any difference between the specimens. 

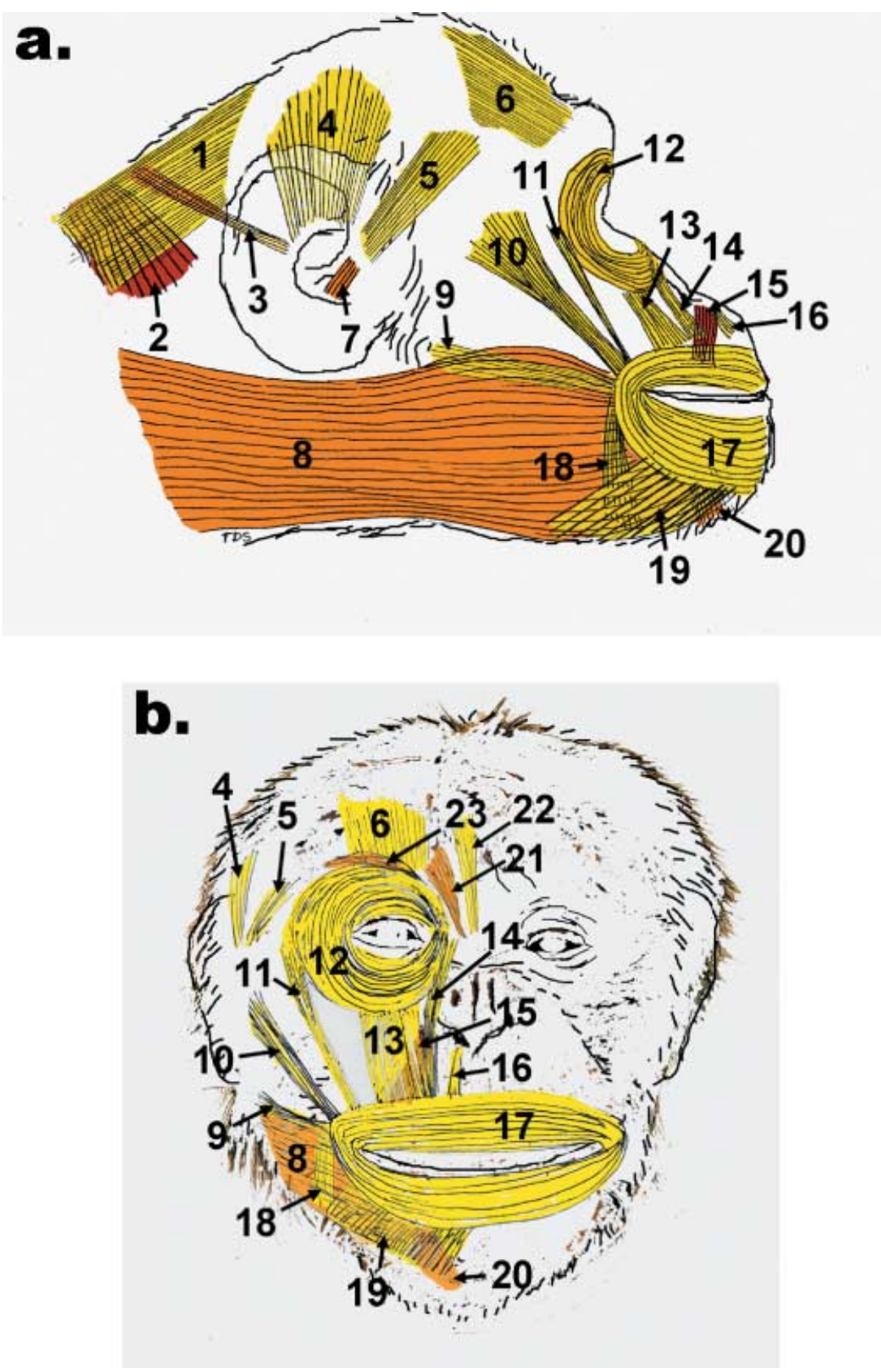

Fig. 1 Abstracts of facial expression musculature in Pan troglodytes. (a) Lateral view; (b) frontal view. In both diagrams, yellow represents the most superficially located musculature, red represents the most deeply located musculature and orange represents muscles located intermediate to the others. For both views: 1 - superficial head, occipitalis muscle, 2 - deep head, occipitalis muscle, 3 - posterior auricularis muscle, 4 - superior auricularis muscle, 5 - anterior auricularis muscle, 6 - frontalis muscle, 7 -tragicus muscle, 8 - platysma muscle, 9 - risorius muscle, 10 - superficial head, zygomaticus major muscle, 11 - zygomaticus minor muscle, 12 orbicularis occuli muscle, 13 - levator labii superioris muscle, 14 - levator labii superioris alaeque nasi muscle, 15 - caninus muscle, 16 - depressor septi muscle, 17 - orbicularis oris muscle, 18 - depressor anguli oris muscle, 19 - depressor labii inferioris muscle, 20 - mentalis muscle, 21 - depressor supercilli muscle, 22 - procerus muscle, and 23 -corrugator supercilli muscle.

\section{Results}

Figure 1 shows all of the musculature in place in normal context. Figures 2-6 show the mimetic musculature located in the present study, region by region. Gross examination between the two specimens revealed no obvious differences in muscle presence, fibre orientation or attachments. However, the platysma muscle, occipitalis muscle, frontalis muscle and all muscles of the superciliary region were unavailable for observation in the $\mathrm{CMZ}$ specimen as the neck and superciliary region were not available. The mental attachments of platysma were, however, available in the CMZ specimen.

Both specimens possessed relatively thick skin with generous quantities of fascia between the dermis and musculature, especially in the oral region. Unlike Homo, there was very little adipose in any region of the face (see Stranding, 2004). In the occipital region, over the lateral portion of the midface, the oral region and the superciliary region, the superficial fascia was intimately adherent to the underlying muscles (such as the deep head of the occipitalis muscle, the depressor 
Fig. 2 Right side of facial mask from Pan troglodytes. This is a view of the deep surface of the face as dissected away from the skull.

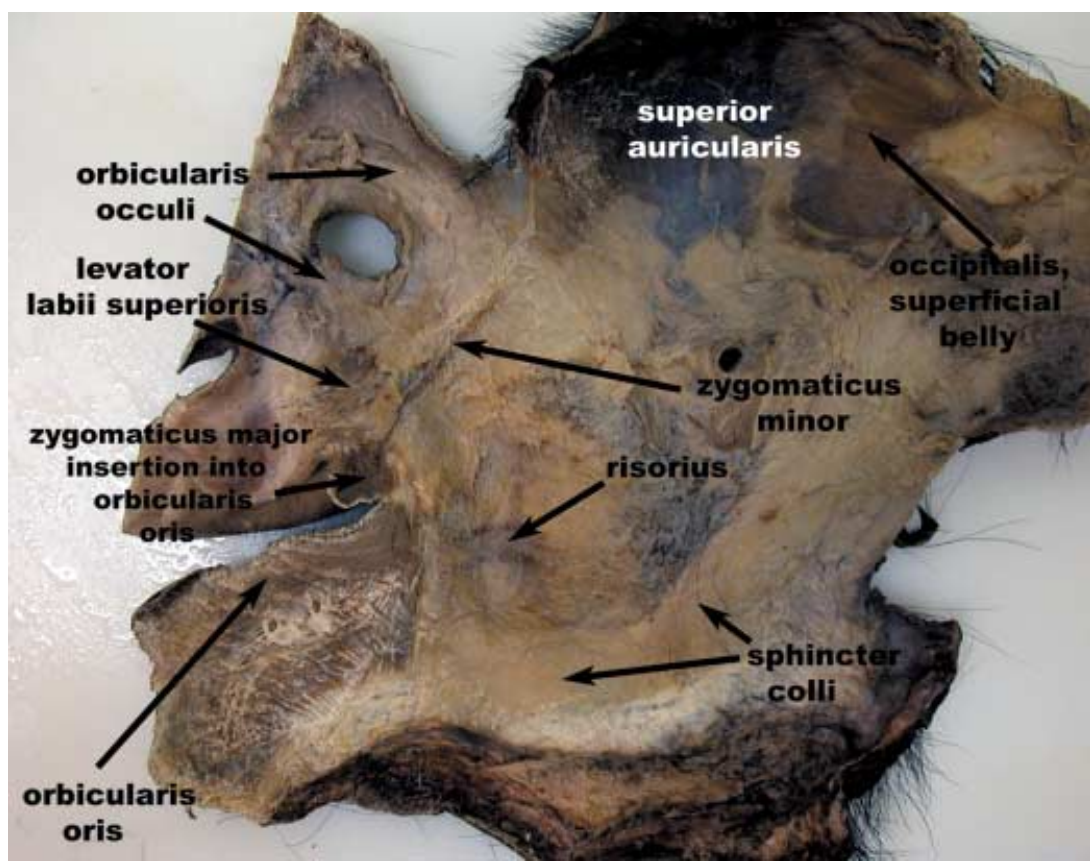

supercilli muscle and the zygomaticus major muscle), such that the scalpel blade frequently had to be used to free the muscle fascicles from the overlying fascia. The more superficially located muscles (such as the superficial head of the occipitalis muscle, the zygomaticus minor muscle and the risorius muscle) were frequently intermingled with fascia. The remaining muscles were robust, attached to discrete portions of the dermis or cartilaginous pinna, skull and/or into other muscles.

In general, the muscles associated with the scalp and pinna were fairly gracile whereas the muscles associated with the oral region were the thickest and largest. Muscles associated with the orbital region were intermediate in size (see Figs 2-6).

\section{Individual muscles (see Table 1 and Figs 1-6)}

Platysma muscle (Figs 1 and 3)

This muscle is flat, thin and broad with fibres running horizontally from the cervical region, passing inferior to the pinna and attaching partially into the oral modiolus. More inferiorly located fibres pass along the ventral aspect of the neck and attach into the mental region, mingling with fibres of the orbicularis oris muscle of the lower lip. This muscle is directly deep to the skin with only weak attachments to the skin itself. It lies deep to the risorius muscle but superficial to the deep head of the occipitalis muscle, the mentalis muscle, and the depressors anguli and labii inferioris muscles. It has a firm attachment to the superficial head of the occipitalis muscle. Huber (1931) describes this muscle in $P$. troglodytes as having lost its occipital and cervical portions, but these are quite robust in the present specimens.

Sphincter colli muscle (Figs 1, 2 and 6)

This muscle is consistently noted in the prosimian primates but has not been described for anthropoids. Here, there is a thickened layer of the superficial fascia along the lateral portion of the face stretching from the region of the oral commissure to the inferior border of the mandible, passing caudally to the skin of the region of the mandibular ramus. The fibres here are fleeting and sparse, located superficial to the platysma muscle.

Occipitalis muscle, superficial head (Figs 1, 2 and 4)

This is a small, flat muscle embedded within the superficial fascia associated with the occipital region. Horizontal fibres pass from the fascia in the occipital region to the deep head of the occipitalis muscle, to which it fuses. Where the superficial head terminates over the calvaria, the galea aponeurotica begins. Pellatt (1979b) described this muscle as only a thin, fibrous sheet, but it is a quite distinct, muscular structure in the specimens studied here. 
Table 1 Muscles of facial expression in Pan

\begin{tabular}{|c|c|}
\hline Muscle & Attachments \\
\hline platysma & $\begin{array}{l}\text { occipitalis superficial m., modiolus, inferior aspect of orbicularis oris m., skin inferior to pinna back to } \\
\text { occipital region and forward to zygomatic arch region and ventrally over the neck }\end{array}$ \\
\hline sphincter colli & $\begin{array}{l}\text { fleeting fibres from oral commissure and slightly inferior to region of opening for ear canal over the area } \\
\text { of the mandibular ramus }\end{array}$ \\
\hline occipitalis (superficial belly) & $\begin{array}{l}\text { fleeting fibres mixed with superficial fascia, attached to the skin of the posterolateral scalp and to the } \\
\text { platysma muscle and the occipitalis muscle deep belly }\end{array}$ \\
\hline occipitalis (deep belly) & $\begin{array}{l}\text { large robust fibres from the superior nuchal crest next to the insertion of the trapezius muscle to attach } \\
\text { into the deep surface of the caudal fibres of platysma }\end{array}$ \\
\hline muscle frontalis & galea aponeurotica of the scalp to the skin of the superciliary region as a flat sheet \\
\hline anterior auricularis & $\begin{array}{l}\text { anterolateral portion of scalp to the auricular cartilage near the junction of the helix and antihelix as one } \\
\text { large fan of fibres the auricular cartilage near the base of the antihelix as a broad, flat sheet }\end{array}$ \\
\hline posterior auricularis & $\begin{array}{l}\text { from the occipital bone at the superior nuchal crest to the posteiror portion of the pinna at the base of the } \\
\text { antihelix as one robust set of fibres }\end{array}$ \\
\hline tragicus & skin over the lateral aspect of the midface close to the zygomatic arch region and the tragus \\
\hline orbicularis occuli & $\begin{array}{l}\text { gracile, sphincter-like fibres attached to the skin of the eyebrow, eyelid, and around orbital opening } \\
\text { (orbital part); attached to zygomaticus minor, levator labii superioris, and depressor supercilli muscles and } \\
\text { to the frontal and lacrimal bones via the medial palpebral ligament }\end{array}$ \\
\hline corrugator supercilli & $\begin{array}{l}\text { deep to orbicularis occuli muscle fibres; attached to skin of superciliary region and to medial portion of the } \\
\text { bony orbit near the palpebral ligament }\end{array}$ \\
\hline depressor supercilli & $\begin{array}{l}\text { on same level with corrugator supercilli m.; attached to skin over lateral aspect of nose, medial to } \\
\text { orbicularis occuli muscle, to skin of medial portion of eyebrow proce on same level with orbicularis occuli } \\
\mathrm{m} \text { and deep to depressor supercilli m.; attached to skin over lateral aspect of nose, medial to orbicularis } \\
\text { occuli muscle, to skin superior to eyebrow }\end{array}$ \\
\hline zygomaticus major & $\begin{array}{l}\text { by two heads: deep head from lateral portion of zygomatic arch; superficial head from skin over zygomatic } \\
\text { arch; heads join about half of the way down and attach into orbicularis oris muscle at the modiolus }\end{array}$ \\
\hline zygomaticus minor & $\begin{array}{l}\text { small fibres from skin superficial to zygoma and from the lateral portion of orbicularis occuli muscle to } \\
\text { orbicularis oris muscle, medial to zygomaticus major muscle }\end{array}$ \\
\hline levator labii superioris & $\begin{array}{l}\text { large set of flat fibres from skin of midface and from the inferior fibres of orbicularis occuli muscle to skin } \\
\text { of upper lip lateral to insertion of levator labii superioris alaeque nasi muscle and to the orbicularis oris } \\
\text { muscle }\end{array}$ \\
\hline levator labii superioris & medial to levator labii superioris muscle, from medial part of the bony orbit to skin of upper lip just medial \\
\hline alaeque nasi & to insertion of levator labii superioris muscle and to this muscle itself \\
\hline depressor septi & $\begin{array}{l}\text { small set of fibres from skin around the nares to the orbicularis oris muscle caninus deep to levator labii } \\
\text { superioris muscle; wide, flat set of fibres from maxilla to skin of upper lip and orbicularis oris muscle }\end{array}$ \\
\hline risorius & $\begin{array}{l}\text { fleeting horizontal fibres attached to the orbicularis oris muscle to skin over inferolateral portion of face; } \\
\text { superficial to and separate from platysma muscle }\end{array}$ \\
\hline orbicularis oris & $\begin{array}{l}\text { multilayered set of sphincter fibres attached to the alveolar margins of the maxilla and mandible and to } \\
\text { the skin of the lips; attachments to levator labii superioris alaeque nasi, levator labii superioris, caninus, and } \\
\text { zygomaticus major and minor muscles superiorly and to platysma, risorius, mentalis, and depressor anguli } \\
\text { and labii inferioris muscles inferiorly }\end{array}$ \\
\hline depressor anguli oris & $\begin{array}{l}\text { superficial to mentalis platysma muscles; from inferior portion of orbicularis oris muscle near the modiolus } \\
\text { to skin near inferior border of mandible }\end{array}$ \\
\hline depressor labii inferioris & $\begin{array}{l}\text { superficial to mentalis and platysma muscles; from inferior border of orbicularis oris muscle to skin near } \\
\text { inferior border of mandible }\end{array}$ \\
\hline mentalis & $\begin{array}{l}\text { short, thick fibres superficial to platysma muscle attached to inferior portion of orbicularis oris muscle and } \\
\text { to the skin over the mental region }\end{array}$ \\
\hline
\end{tabular}

\section{Occipitalis muscle, deep head (Figs 1 and 3)}

As noted by Pellatt (1979b), this is a thick, robust muscle deep to the platysma muscle and the superficial head of the occipitalis muscle. It has an extensive bony origin from the superior nuchal crest immediately lateral to the trapezius muscle but medial to the posterior auricularis muscle. It passes inferolaterally, deep to the platysma muscle, to which it fuses. Sonntag (1923) described only a single occipitalis muscle, attaching to the bony landmarks corresponding to those found here for the deep head.

\section{Frontalis muscle (Figs 1 and 2)}

This is a flat, very thin sheet of muscle composed of fibres that run from a caudal attachment at the galea 

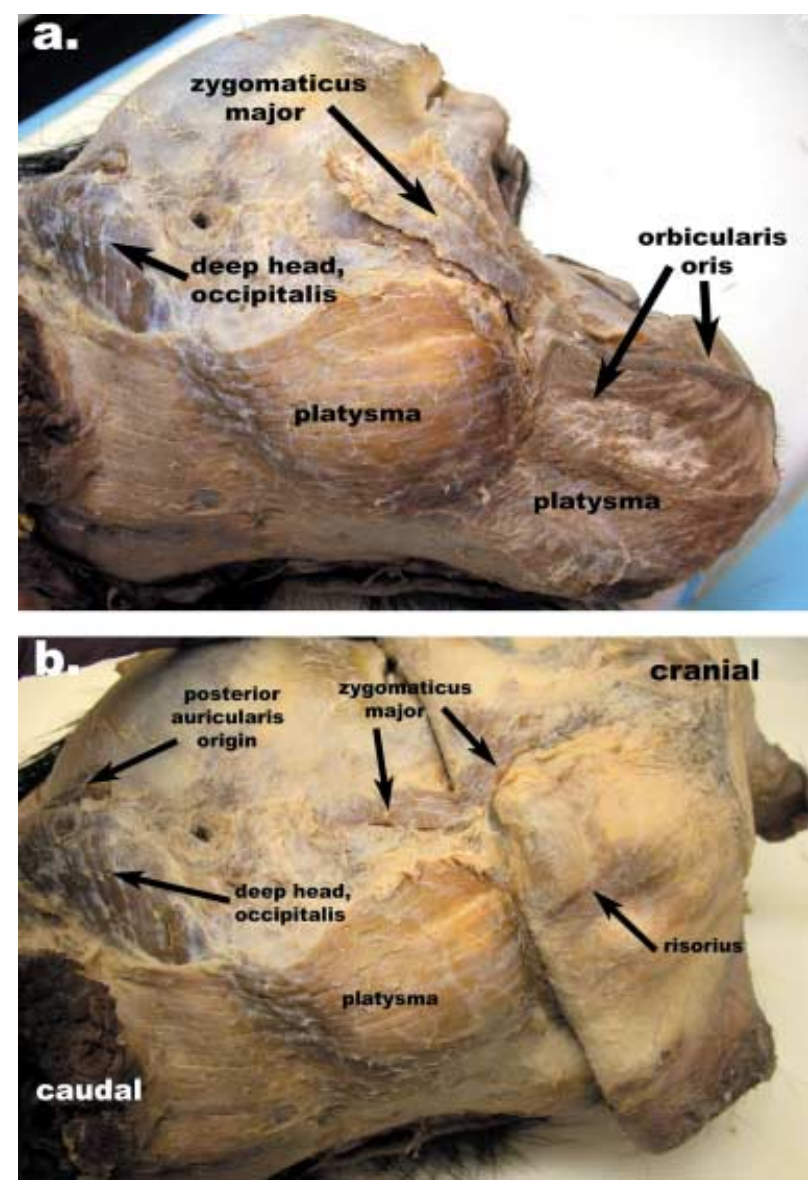

Fig. 3 Right side of head from Pan troglodytes. (a) Dissection of the platysma muscle and its attachments to the orbicularis oris and occipitalis (deep head) muscles. The portion of the zygomaticus major muscle shown here is the superficial head. (b) Dissection of the facial mask away from the deeper structures. Note the more caudal fibres of risorius muscle and the deep and superficial heads of zygomaticus major muscle.

aponeurotica to a cranial attachment into the skin associated with the superciliary region, just caudal to the eyebrow. These fibres are separated from the superior edge of the orbicularis occuli muscle by a narrow cleft, contrasting with the findings of Sonntag (1923). The frontalis muscle is superficial to the corrugator and depressor supercilli muscles but on the same level as the orbicularis occuli muscle.

\section{Anterior auricularis muscle (Figs 1 and 2)}

This is a flat, fan-shaped set of fibres that passes inferolaterally from the skin over the lateral margin of the orbit to the cartilaginous pinna at the anterior portion of the junction between the helix and antihelix.
Superior auricularis muscle (Figs 1, 2 and 4)

This is a flat but thick collection of expansive fibres from the skin of the superolateral portion of the scalp. These fibres run inferolaterally to the superior portion of the junction between the helix and antihelix. Pellatt (1979b) described the anterior and superior auricularis muscles as appearing to be one large sheet of muscle attaching to the pinna in a nearly convergent manner. However, in the present specimens they are distinct muscles separated by fascia and attaching to the pinna at distinct points.

\section{Posterior auricularis muscle (Figs 1, 3 and 4)}

This muscle is the smallest of the auricularis group but is the thickest. It has a discrete bony attachment to the lateral aspect of the superior nuchal crest, superolateral to the deep head of the occipitalis muscle. These fibres are oblique and attach into the posterior portion of the base of the antihelix. Whereas Pellatt (1979b) shows this muscle as consisting of two separate bands in P. troglodytes, it is represented as a single muscle here.

\section{Tragicus muscle (Figs 1 and 2)}

This is a small, fan-shaped muscle located along the inferior aspect of the pinna. It passes in a superocranial direction from the tragus to the skin over the lateralmost portion of the zygomatic arch. The tragicus muscle lies deep to the auricularis muscles. Pellatt (1979b) did not describe this muscle.

Orbicularis occuli muscle (Figs 1, 2, 5 and 6)

This is a thin, sphincter-like muscle with a large orbital part and a small, transversely arranged palpebral part over the eyelid. It is firmly attached to the skin surrounding the orbit but it does not extend caudally beyond the eyebrow. Its inferior extent is much longer, to the skin approximately one-third of the way to the upper lip. There is a firm bony origin from the lacrimal and frontal bones via the medial palpebral ligament. It lies superficial to the corrugator and depressor supercilli muscles but is on the same level as the procerus muscle. Inferiorly, it is attached to the levator labii superioris muscle; medially, it is attached to the levator labii superioris alaeque nasi muscle; laterally it bears an attachment to the zygomaticus minor muscle. 

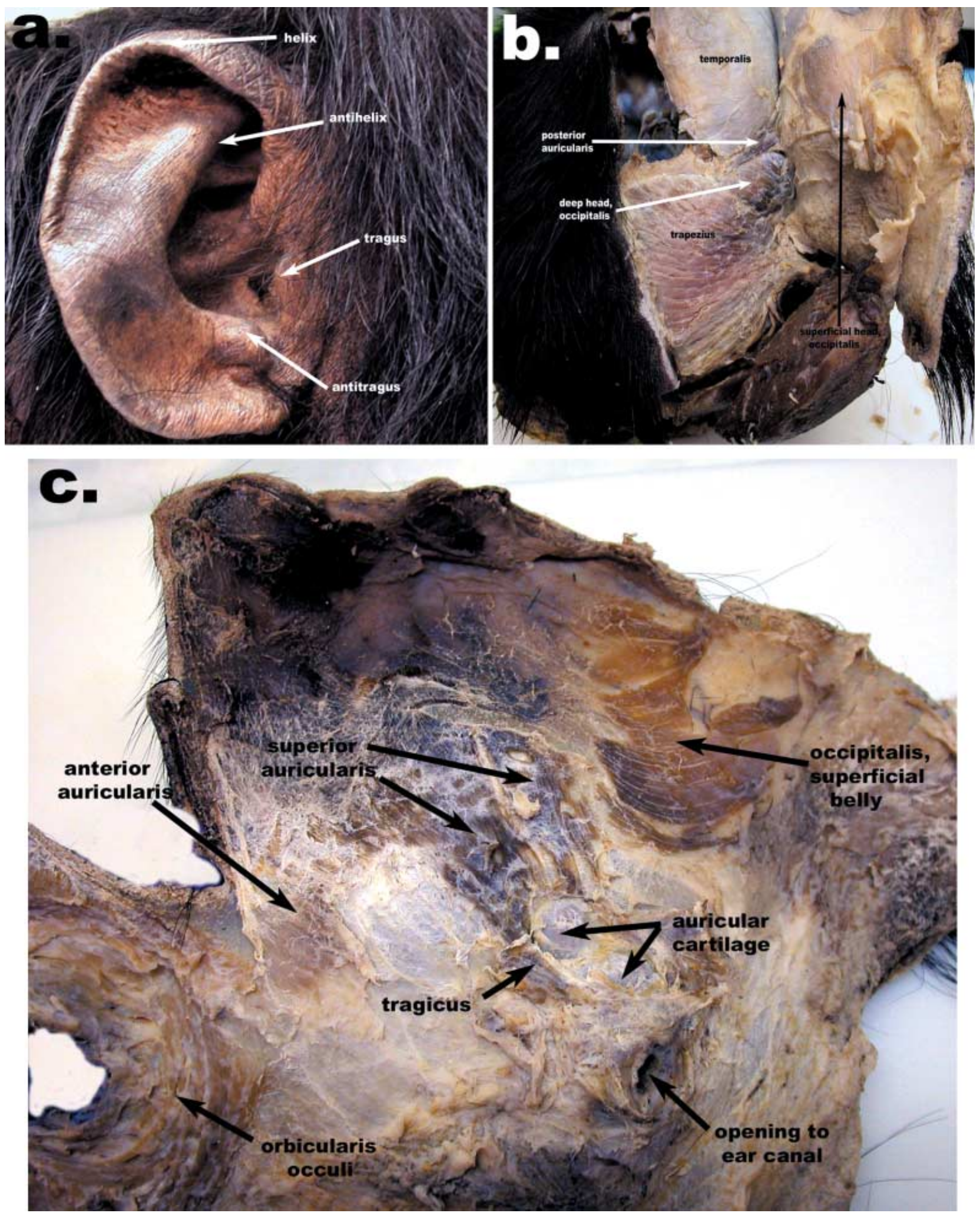

Fig. 4 Composite figure of the (a) right pinna, (b) right occipital region from a caudal view, and (c) right scalp and pinna region from the deep surface of the facial mask. 


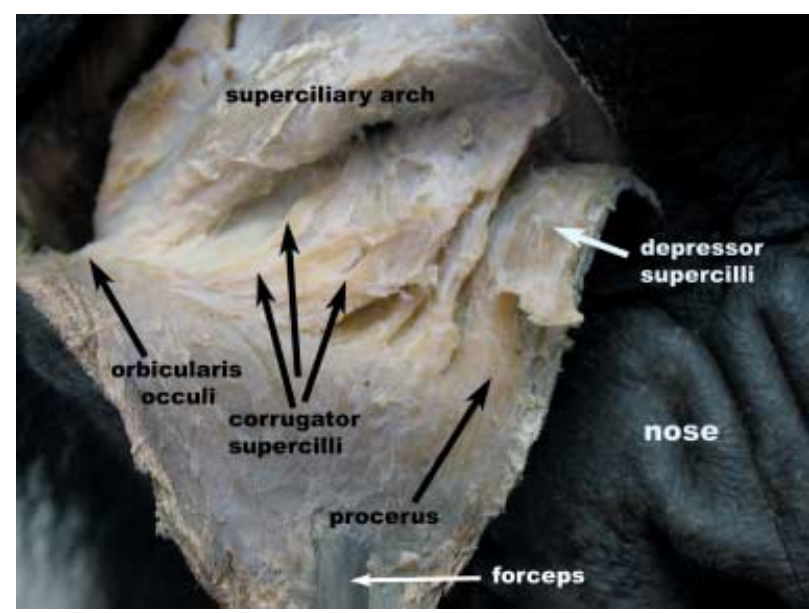

Fig. 5 Right side of face from Pan troglodytes with superciliary region shown in dissection. This is a skin flap from the frontal region pulled down to the level of the superciliary arch.

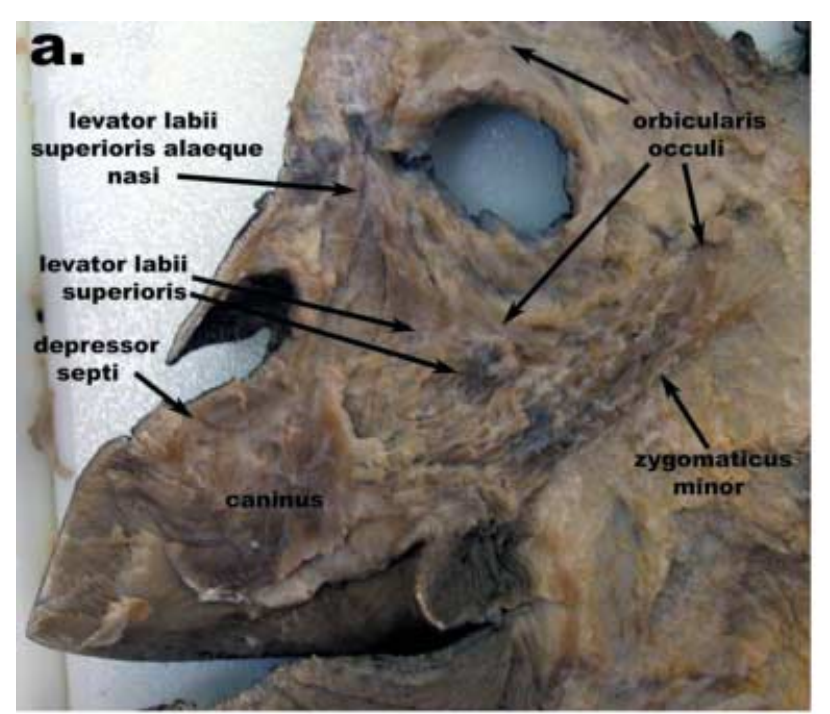

Corrugator supercilli muscle (Figs 1 and 5)

This large muscle lies deep to the orbicularis occuli muscle, attaching inferomedially to the frontal bone at the medial root of the superciliary arch. From this attachment, four separate flat, fan-shaped bundles diverge superolaterally and attach into the skin of the superior border of the eyebrow, superior and deep to the orbicularis occuli muscle. Pellatt (1979b) described the corrugator as being barely distinguishable in P. troglodytes.

\section{Depressor supercilli muscle (Figs 1 and 5)}

The depressor is a set of vertically orientated fibres located medial to the corrugator supercilli muscle,

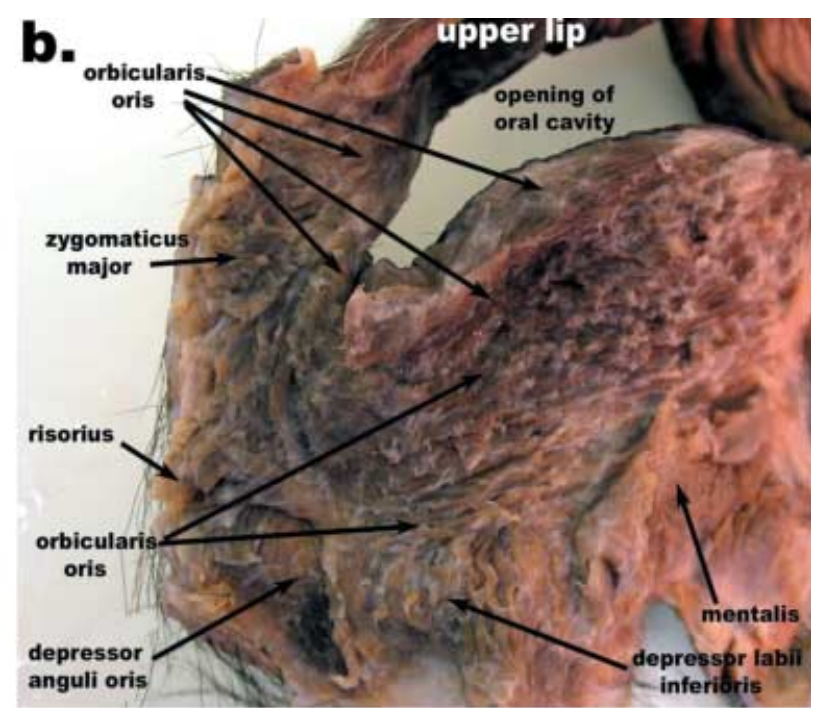

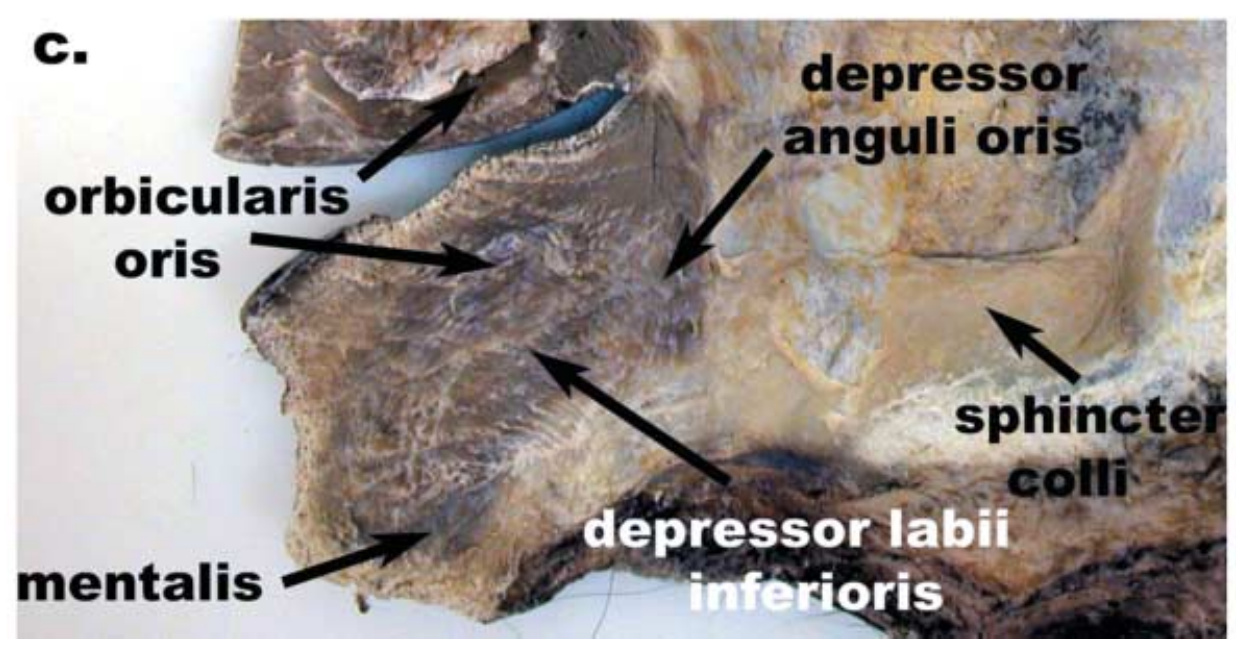

Fig. 6 Composite figure of the (a) right midfacial and orbital regions, (b) orbicularis oris muscle and associated musculature, and (c) right lower lip and mental regions. All figures are of the deep surface of the facial masks. Note the especially thick and expansive orbicularis oris muscle in Pan troglodytes. 
attaching inferiorly to the skin over the nasal bone and ascending to attach into the skin of the medial portion of the eyebrow. This muscle lies deep to the procerus muscle and was not described by Pellatt (1979b).

Procerus muscle (Figs 1 and 5)

The procerus is a flat, thin and vertically orientated sheet of fibres passing from an inferior attachment to the skin over the nasal bone, but slightly lateral to the depressor supercilli muscle. It attaches superiorly to the skin over the frontal bone, superior to the eyebrow but stopping inferior to the frontalis muscle. This muscle is grossly similar to that illustrated in Pellatt (1979b).

\section{Zygomaticus major muscle (Figs 1-3 and 6)}

Unlike in previous descriptions (Sonntag, 1923; Pellatt, 1979b), this muscle possesses a deep head, attached caudally to the zygomatic arch, and a superficial head, attached throughout to the skin over the superolateral portion of the face. The deep head fibres are arranged more transversely whereas the fibres of the superficial head are more oblique. The heads fuse approximately half of the way through their courses and attach together into the lateral-most portion of the orbicularis oris muscle with a brief attachment into the corresponding skin. This muscle (both heads) is lateral to the zygomaticus minor muscle.

\section{Zygomaticus minor muscle (Figs 1, 2 and 6)}

This muscle lies medial to the zygomaticus major muscle and is a highly gracile, superficially located collection of fibres. It is attached superiorly to the skin over the zygoma near its junction with the zygomatic arch. Here, it is attached to the orbicularis occuli muscle but is clearly a distinct muscle. Inferiorly, it is attached to the orbicularis oris muscle at the medial edge of the attachment for the zygomaticus major muscle. It is described in Pellatt (1979b) as incipient, being merely part of the orbicularis occuli muscle.

Levator labii superioris muscle (Figs 1 and 6)

This is a large, flat muscle taking up most of the midface. It has a broad superior attachment to the orbicularis occuli muscle and to the skin over the maxilla. Inferiorly it attaches into the skin of the upper lip and into the orbicularis oris muscle, between the levator labii superioris alaeque nasi and the zygomaticus minor muscles.

Levator labii superioris alaeque nasi muscle (Figs 1 and 6)

This narrow muscle is composed of vertically orientated fibres medial to the levator labii superioris muscle. Its superior attachment is to the skin over the region of the medial palpebral ligament and from the lacrimal bone medially. Inferiorly, it is attached into the skin around the lateral margin of the nares and into the medial edge of the levator labii superioris muscle.

Depressor septi muscle (Figs 1 and 6)

This muscle is small and vertically orientated, attaching superiorly to the skin around the inferolateral boundary of the nares. Inferiorly, it attaches into the orbicularis oris muscle of the upper lip. It was not described by Pellatt (1979b), and Sonntag (1923) stated that it is absent.

\section{Caninus muscle (Figs 1 and 6)}

The caninus is located deep to the depressor septi, levator labii superioris alaeque nasi and levator labii superioris muscles. It is attached superiorly to the maxilla at a level midway down the piriform crest. Inferiorly, it is attached to the skin of the upper lip and to the orbicularis oris muscle. It was not described by Pellatt (1979b).

\section{Risorius muscle (Figs 1-3 and 6)}

This is a thin set of fibres that passes horizontally from a cranial attachment at the junction of the orbicularis oris and depressor anguli oris muscles, caudally to the skin superficial to the platysma muscle. The risorius muscle stops approximately halfway over the masseter region. It was not described at all by Pellatt (1979b) but is described as part of the platysma muscle by Sonntag (1923). Here, it is completely divorced from the platysma muscle.

Orbicularis oris muscle (Figs 1, 2 and 6)

The orbicularis oris is an exceptionally thick, multilayered sphincter muscle surrounding the opening of the oral cavity. Its superior extent is not as great as its 
inferior extent, which reaches a level approximately half of the way to the skin over the inferior border of the mandible. It is attached superficially into the skin of the lips. The deeper fibres are attached to the alveolar margins of the maxilla and mandible. The superficial and deep fibres are firmly attached to one another and decussate at the modiolar region, receiving there parts of the zygomaticus major, the depressor anguli oris and the risorius muscles. The maxillary portion of the orbicularis oris muscle receives part of the zygomaticus major and minor muscles, the levator labii superioris, levator labii superioris alaeque nasi, caninus and depressor septi muscles. The mandibular portion receives the platysma muscle and the depressor labii inferioris muscle. The mandibular portion also holds collections of labial glands.

\section{Depressor anguli oris muscle (Figs 1 and 6)}

This is a robust set of fibres passing lateral to medial. It is attached superiorly to the modiolar region of the orbicularis oris muscle and inferiorly to the skin about two-thirds of the way to the level of the inferior border of the mandible. The depressor anguli oris muscle lies lateral and deep to the depressor labii inferioris muscle and superficial to the platysma muscle. It is only weakly interlaced with the platysma muscle, contrary to the description in Pellatt (1979b).

\section{Depressor labii inferioris muscle (Figs 1 and 6)}

This is a flat, broad muscle attached superiorly to the inferior border of the orbicularis oris muscle almost to the midline of the face. It is attached to the skin over the mandibular body to a level approximately twothirds of the way to the region of the inferior border of the mandible. It is superficial to and clearly distinct from the platysma muscle, contrary to the description given by Pellatt (1979b).

\section{Mentalis muscle (Figs 1 and 6)}

The mentalis muscle is a small but robust muscle composed of fan-shaped fibres. Inferiorly, it is attached to the skin over the midline of the mandible at a relatively concise point. The fibres diverge in a fan-like fashion and attach superiorly to the skin over the inferior border of the depressor labii inferioris muscle. It lies deep to the depressor labii inferioris muscle.

\section{Discussion}

The present study described a variety of facial muscles in Pan troglodytes that have not been previously described or have been debated as to their existence (Sonntag, 1923; Pellatt, 1979b). These include the risorius muscle, the depressor septi muscle, the corrugator supercilli and depressor supercilli muscles, the sphincter colli muscle, and the caninus muscle. Additionally, this study located deep and superficial heads of the zygomaticus major muscle. Clearly, the muscles of facial expression in $P$. troglodytes are far more complex than previously described and are far more similar to the arrangement seen in Homo than previously reported. Part of the explanation for the greater number of muscles located in the present study may be due to the methodology. This study removed the face from the skull, preserving and separating the superficially located musculature (e.g. the risorius and zygomaticus minor muscles) from the more deeply located musculature (e.g. the levator labii superioris muscle). By using this methodology instead of the more traditional method of removing the skin and attempting to leave behind all of the musculature with the skull, a greater number of muscles may have been preserved.

In the scalp/pinna region, the present study confirms the findings of Pellatt (1979b) in locating a superficial and a deep head of the occipitalis muscle, but here a firm fusion of these muscles was located cranially. Whereas Huber (1931) described the occipitalis muscle as being nearly vestigial, it is likely that he was describing only the superficial head of this muscle. Similarly, Sonntag (1923) described the occipitalis muscle only as being attached to the occipital bone; it is probable that he was describing only the deep head. In contrast to the findings of Pellatt (1979b), we found the superior and anterior auricularis muscles to be distinct from one another. Whereas Huber (1931) described a robust tragohelicis muscle, none was found in the present study. However, and perhaps more importantly, a robust tragicus muscle was found in the present study, which Huber (1931) cites as being unique to Homo.

In the superciliary/orbital region, robust corrugator and depressor supercilli muscles were found, in agreement with Huber (1931). This is of interest given differing reports of the presence of frowning in chimpanzees (Pellatt, 1979b; Ladygina-Kohts, 2002; Parr et al. 2002). However, the procerus muscle is completely divorced 
from the frontalis muscle, contrary to the findings of Huber (1931). In the midface, the zygomaticus major muscle was found to possess both a deep head and a large superficial head, contrary to previous studies (Sonntag, 1923; Huber, 1931; Pellatt, 1979b). Pellatt (1979b) described a zygomaticus major muscle and a separate, medially located malaris muscle. However, he showed these muscles as being arranged in a lateral to medial relationship and separate throughout their paths to the upper lip. Thus, it is unlikely that the arrangement of the zygomaticus major muscle found in the present study represents the separate muscles described in Pellatt (1979b). The present study failed to locate, however, a separate malaris muscle. Pellatt (1979a) described a bifid zygomaticus major muscle in Papio ursinus; however, this muscle has a common superior attachment to the temporal bone, later diverging near the upper lip. Finally, the present study located a distinct risorius muscle, a character often considered to be unique to humans (Huber, 1931), but previously described by Sonntag (1923) as being merely a slip from the platysma muscle.

One of the major differences found in the present study between $P$. troglodytes and humans was the firm fusion and, often, intimate infiltration of the superficial fascia into some of the muscles, such as the deep head of the occipitalis muscle, the zygomaticus major muscle, and the depressors anguli oris and labii inferioris muscles. In these muscles, the superficial fascia was firmly blended with the muscle fascicles and slowed progression of the dissection. This is very different from the relationship between the superficial fascia and musculature in human faces (e.g. Stranding, 2004) where the superficial fascia typically lies only loosely on top of the muscle. Whereas the present study has revealed a generally greater anatomical similarity in the facial muscles between chimpanzees and humans, it has long been held that chimpanzees do not have as varied a facial signalling repertoire as seen in humans (e.g. van Hooff, 1972, 1973; Preuschoft, 2000). It is possible that the differential arrangement of the superficial fascia over the face may affect the ability of the facial muscle in question to contract in $P$. troglodytes, potentially reducing the resultant mobility of the facial mask in any given region. Further investigation into the histological arrangement of the fascia with the muscle fascicles is needed in order to answer this question, however.

As in Homo, the facial expression musculature in $P$. troglodytes was thickest and most numerous in the area of the oral cavity. P. troglodytes lives in loose multi-male/multi-female fission-fusion communities where the large group may frequently break out into numerous small groups, interact with other groups and then reunite (Nishida, 1979). Males are generally dominant with a clear dominance hierarchy and frequent territorial disputes (Goodall, 1986). In these intricate social settings, a variety of vocal, chemical and visual communication modes are employed to send information on social intentions, emotional states, and various aspects of an individual such as age, sex and reproductive status (de Waal \& Aureli, 1996; Parr, 2003). $P$. troglodytes is reported to use a number of facial expressions to communicate various intentions (van Hooff, 1972, 1973; de Waal \& van Roosmalen, 1979; Goodall, 1986; Parr et al. 1998). Many of these facial expressions in social contexts are reported to feature movements of the lips such as the silent bared-teeth and relaxed open-mouth displays (van Hooff, 1972; Parr et al. 1998; Waller \& Dunbar, 2005), and very few displays are noted to include movements of the orbital region, scalp or pinna. The preponderance of musculature associated with the oral region may indeed reflect these behavioural observations for $P$. troglodytes.

\section{Comparative and phylogenetic considerations}

Gross muscle findings from the present study provide some insight into both the behavioural aspects of $P$. troglodytes facial expression and the evolution of primate facial expression and its associated musculature. Most work into primate facial expression, both anatomical and behavioural, has used as a foundation the notion that the complexity of muscles increases from the most primitive primates, the lorisoids (Prosimii: Lorisiformes), to the catarrhines (Anthropoidea: Catarrhini), and on into the hominoids, with the highest level of complexity being found in the hominines (Catarrhini: Hominoidea: Hominidae: Homininae), Homo being situated at the apex of the scale (Murie \& Mivart, 1872; Ruge, 1885; Gregory, 1929; Huber, 1931; Schultz, 1969).

Recent work, however, has called this foundational framework into question (Burrows \& Smith, 2003), finding far greater complexity in lorisoid musculature than previously reported. In addition, facial musculature found in $P$. troglodytes in the present study similarly is more complex than previously reported. Indeed, the musculature found here in $P$. troglodytes shows 
only minimal difference from that of Homo (e.g. the presence of deep and superficial heads of occipitalis muscle). The presence of deep and superficial heads of zygomaticus major muscle is not particularly surprising, given the great variation in the structure of this muscle in Homo (e.g. Stranding, 2004). Aside from the minor variations, there is no foundation for claiming greater complexity in Homo facial expression musculature.

The muscles of the scalp and pinna regions are greatly reduced in $P$. troglodytes compared with those of a typical lorisoid, Otolemur (greater galago) (Burrows \& Smith, 2003). Otolemur possesses a number of muscles that connect the scalp to the pinna (e.g. attrahens aurem and occipitofrontalis muscles) and small, discrete muscles that move the pinna (e.g. atollens aurem and retrahens aurem muscles). In Otolemur, the majority of facial expression musculature is located around the pinna and in connections between the pinna and the lips (e.g. the auriculolabialis muscles) (Burrows \& Smith, 2003). Very little musculature is located in the midface and only a small number of muscles are connected to the lips, contrary to the scenario in $P$. troglodytes and Homo. Behavioural studies report the frequency of pinna movements in Otolemur, both for hunting purposes and in social contexts (Charles-Dominique, 1977; AnkelSimons, 2000), while the connections between the pinna and lips may represent mechanisms for drawing back the lips in use of the vomeronasal organ, which is quite large in Otolemur (Smith et al. 2001, 2002; Dennis et al. 2004), similar to the behaviour seen in Lemur catta (Bailey, 1978).

As facial expression musculature is examined in catarrhines from cercopithecoids up to Homo (Huber, 1933; Pellatt, 1979a), the discrete individual muscles associated with the pinna and the connections between the pinna and lips in lorisoids is no longer apparent. Instead, there is a concentration on musculature associated with the upper lip (Huber, 1931, 1933; Andrew, 1963; van Hooff, 1973; Swindler \& Wood, 1982). Indeed, many of the facial displays of catarrhines, including Homo, concentrate on movements of the upper lip and midface in general (e.g. Preuschoft, 2000; Ekman et al. 2002; Waller \& Dunbar, 2005) with a corresponding decrease in relative size of the vomeronasal organ (Smith et al. 2001, 2002). Given the results of the present study, Burrows \& Smith (2003) and Sherwood et al. (2003, 2005), the traditional 'phylogenetic framework', sensu Huber, seems to be a questionable model for under- standing primate facial expression and its evolution. Given the call for increased emphasis on soft-tissue anatomy in phylogenetic analyses (Gibbs et al. 2002), future studies using both a wider taxonomic sample along with functional and developmental data may indeed shed light on the phylogenetic basis of primate facial musculature.

\section{Acknowledgements}

This study was supported by the Leverhulme Trust, grant number F/00678/E. We wish to thank Kim A. Bard for germinating the seeds of the current study in her project to develop a facial action coding system for chimpanzees from the Leverhulme Trust. We also wish to thank the three reviewers for providing numerous helpful suggestions. Figure 1 was drawn by Tim D. Smith.

\section{References}

Andrew RJ (1963) The origin and evolution of the calls and facial expressions of the primates. Behaviour 20, 1-109.

Ankel-Simons F (2000) Primate Anatomy, 2nd edn. San Diego: Academic Press.

Bailey K (1978) Flehmen in the ring-tailed lemur (Lemur catta). Behaviour 65, 309-319.

Bard KA (2003) Development of emotional expressions in chimpanzees (Pan troglodytes). Ann NY Acad Sci 1000, 88 90.

Bearder SK, Honess PE, Ambrose L (1995) Species diversity among galagos, with special reference to mate recognition. In: Creatures of the Dark: the Nocturnal Prosimians (eds Alterman L, Doyle GA, Izard MK), pp. 331-352. Pittsburgh: University of Pittsburgh Press.

Boesch C (2003) Is culture a golden barrier between humans and chimpanzees? Evol Anthropol 12, 82-91.

Burrows AM, Smith TD (2003) Muscles of facial expression in Otolemur, with a comparison to Lemuroidea. Anat Rec 274A, 827-836.

Charles-Dominique P (1977) Ecology and Behavior of Nocturnal Primates. New York: Columbia University Press.

Darwin CR (1872) The Expression of Emotions in Man and Animals. London: J. Murray.

Dennis JC, Smith TD, Bhatnagar KP, Burrows AM, Bonar CJ, Morrison EE (2004) Expression of neuron-specific markers by the vomeronasal neuroepithelium in six primate species. Anat Rec 281, 1190-1200.

Duchenne de Boulogne C-B (1862 - translated 1990) The Mechanism of Human Facial Expression (ed. Cuthbertson RA). Cambridge: Cambridge University Press.

Ekman P (1973) Darwin and Facial Expression; a Century of Research in Review. New York: Academic Press.

Ekman P, Oster H (1979) Facial expressions of emotion. Ann Rev Psych 20, 527-554. 
Ekman P, Friesen WV, Hager JC (2002) Facial Action Coding System. Salt Lake City: Research Nexus.

Fagot J, Bard KA (1995) Asymmetrical-grasping response in neonate chimpanzees (Pan troglodytes). Inf Beh Dev 18, 253-255.

Gibbs S, Collard M, Wood B (2002) Soft-tissue anatomy of the extant hominoids: a review and phylogenetic analysis. $J$ Anat 200, 3-49.

Goodall J (1986) The Chimpanzees of Gombe: Patterns of Behavior. Cambridge: Harvard University Press.

Gregory WK (1929) Our Face from Fish to Man. New York: G.P. Putnam's Sons.

Groves C (2001) Primate Taxonomy. Washington, DC: Smithsonian Institution.

Hicks TC, Fouts RS, Fouts DH (2005) Chimpanzee (Pan troglodytes troglodytes) tool use in the Ngotto Forest, Central African Republic. Am J Primatol 65, 221-237.

van Hooff JARAM (1962) Facial expressions in higher primates. Symp Zool Soc London 8, 97-125.

van Hooff JARAM (1972) A comparative approach to the phylogeny of laughter and smile. In: Nonverbal Communication (ed. Hinde RA), pp. 209-241. Cambridge: Cambridge University Press.

van Hooff JARAM (1973) A structural analysis of the social behaviour in a semi-captive group of chimpanzees. In: Expressive Movement and Nonverbal Communication (eds Von Cranach M, Vine I), pp. 75-161. London: Academic Press.

Hopkins WD, Bard KA, Jones A, Bales S (1993) Chimpanzee hand preference for throwing and infant cradling: implications for the origin of human handedness. Curr Anthropol 34, 786-790.

Huber E (1930a) Evolution of facial musculature and cutaneous field of trigeminus. Part I. Quart Rev Biol 5, 133-188.

Huber E (1930b) Evolution of facial musculature and cutaneous field of trigeminus. Part II. Quart Rev Biol 5, 389-437.

Huber E (1931) Evolution of Facial Musculature and Expression. Baltimore: The Johns Hopkins University Press.

Huber E (1933) The facial musculature and its innervation. In: Anatomy of the Rhesus Monkey (eds Hartman CG, Straus WL Jr), pp. 176-188. New York: Hafner Publishing Co.

Kaiser S (2002) Facial expressions as indicators of 'functional' and 'dysfunctional' emotional processes. In: The Human Face: Measurement and Meaning (ed. Katsikitis M), pp. 235-254. Dordrecht: Kluwer.

Ladygina-Kohts NN (2002) In: Infant Chimpanzee and Human Child: A Classic 1935 Comparative Study of Ape Emotion and Intelligence (ed. de Waal FBM). New York: Oxford University Press.

Lightoller GS (1928) The facial muscles of three orang utans and two ceropithecidae. J Anat 63, 19-81.

Lightoller GS (1934) The facial musculature of some lesser primates and a Tupaia. Proc Zool Soc Lond 1934, 259-309.

Marler P (1965) Communication in monkeys and apes. In: Primate Behavior (ed. DeVore I), pp. 544-584. New York: Holt, Rinehart \& Winston.

Marler P (1976) Social organization, communication, and graded signals: the chimpanzee and the gorilla. In: Growing Points in Ethology (eds Bateson PPG, Hinde RA), pp. 239279. London: Cambridge University Press.
McBrearty S, Jablonski NG (2005) First fossil chimpanzee. Nature 437, 105-108.

Murie J, Mivart St G (1872) On the anatomy of the Lemuroidea. Trans Zool Soc Lond 7, 1-113 + 6 pl.

Nishida T (1979) The social structure of chimpanzees of the Mahale Mountains. In: The Great Apes (eds Hamburg DA, McCown ER), pp. 73-121. Menlo Park, CA: BenjaminCummings.

Parr LA, Hopkins WD, de Waal FBM (1998) The perception of facial expressions by chimpanzees, Pan troglodytes. Evol Comm 2, 1-23.

Parr LA, de Waal FBM (1999) Visual kin recognition in chimpanzees. Nature 399, 147-648.

Parr LA, Preuschoft S, de Waal FBM (2002) Research on facial emotion in chimpanzees: 75 years since Kohts. In: Infant Chimpanzee and Human Child: a Classic 1935 Comparative Study of Ape Emotion and Intelligence (ed. de Waal FBM), pp. 411-452. New York: Oxford University Press.

Parr LA (2003) The discrimination of faces and their emotional content by chimpanzees (Pan troglodytes). Ann NY Acad Sci 1000, 56-78.

Parr LA, Cohen M, de Waal FBM (2005) The influence of social context on the use of blended and graded facial displays in chimpanzees (Pan troglodytes). Int J Primatol 26, 73-103.

Pellatt A (1979a) The facial muscles of Papio ursinus. S Afr J Sci 75, 30-37.

Pellatt A (1979b) The facial muscles of three African primates contrasted with those of Papio ursinus. S Afr J Sci 75, 436440.

Pika S, Liebal K, Tomasello M (2005) Gestural communication in subadult bonobos (Pan paniscus): repertoire and use. Am J Primatol 65, 39-61.

Preuschoft S (2000) Primate faces and facial expressions. Soc Res 67, 245-271.

Preuschoft S, van Hooff JARAM (1995) Homologizing primate facial displays: a critical review of methods. Folia Primatolog 65, 121-137.

Raven HC (1950) Regional anatomy of the gorilla. In: The Anatomy of the Gorilla (ed. Gregory WK), pp. 15-188. New York: Columbia University Press.

Ruge G (1885) Über die Gesichtsmuskulatur der Halbaffen. Morph Jahrb 11, 243-315.

Schmidt KL, Cohn JF (2001) Human facial expressions as adaptations: evolutionary questions in facial expression research. Yearb Phys Anthropol 44, 3-24.

Schultz AH (1969) The Life of Primates. New York: Universe Books.

Seiler R (1975) Die Fazialismuskeln von Perodicticus potto und Nycticebus coucang. Folia Primatol 23, 275-289.

Sherwood CC, Holloway RL, Gannon PJ, et al. (2003) Neuroanatomical basis of facial expression in monkeys, apes, and humans. Ann NY Acad Sci 1000, 99-103.

Sherwood CC, Hof PR, Holloway RL, et al. (2005) Evolution of the brainstem orofacial motor system in primates: a comparative study of trigeminal, facial, and hypglossal nuclei. J Hum Evol 48, 45-84.

Sisson S (1921) The Anatomy of the Domestic Animals. Philadelphia: W.B. Saunders Company. 
Smith TD, Siegel MI, Bhatnagar KP (2001) Reappraisal of the vomeronasal system of catarrhine primates, ontogeny, morphology, functionality, and persisting questions. Anat Rec (New Anat) 265, 176-192.

Smith TD, Bhatnagar KP, Shimp KL, et al. (2002) Histological definition of the vomeronasal organ in humans and chimpanzees, with a comparison to other primates. Anat Rec 267, 827-836.

Sonntag CF (1923) On the anatomy, physiology, and pathology of the chimpanzee. Proc Zool Soc London 23, 323-429.

Stranding S (2004) Gray's Anatomy, 39th edn. London: Churchill Livingstone.

Swindler DR, Wood CD (1982) An Atlas of Primate Gross Anatomy. Malabar, FL: Robert E. Krieger Publishing.

The Chimpanzee Sequencing and Analysis Consortium (2005) Initial sequence of the chimpanzee genome and comparison with the human genome. Nature 437, 69-87.

de Waal FBM, van Roosmalen A (1979) Reconciliation and consolation among chimpanzees. Behav Ecol Sociobiol 5, 55-66.

de Waal FBM, Aureli F (1996) Consolation, reconciliation, and a possible cognitive difference between macaque and chimpanzee. In: Reaching into Thought: the Minds of the Great Apes (eds Russon AE, Bard KA, Parker ST), pp. 80-110. Cambridge: Cambridge University Press.

de Waal FMB (2000) Primates - a natural heritage of conflict resolution. Science 289, 586-590.

Walker WF Jr, Liem KF (1994) Functional Anatomy of the Vertebrates, 2nd edn. Fort Worth: Saunders College Publishing.

Waller BM, Dunbar RIM (2005) Differential behavioural effects of silent bared teeth display and relaxed open mouth display in chimpanzees (Pan troglodytes). Ethology 111, 129-142.

Young JZ (1957) The Life of Mammals. Oxford: Clarendon Press. Young JZ (1962) The Life of Vertebrates. New York: Oxford University Press. 